\title{
石墨烯气凝胶的可控组装
}

\author{
李广勇 ${ }^{1,2}$ 吴晓涵 ${ }^{2}$ 何伟娜 ${ }^{2}$ 方建慧 ${ }^{1, *}$ 张学同 ${ }^{2, *}$ \\ ('上海大学理学院化学系, 上海 200444; ${ }^{2}$ 中国科学院苏州纳米技术与纳米仿生研究所, 江苏苏州 215123)
}

\begin{abstract}
摘要: 石墨烯气凝胶一般是由石墨烯片层经过湿法化学组装或气相化学生长获得的一种具有连通多孔网络结 构的石墨烯三维宏观体材料, 表现出极高的比表面积、良好的导电性以及优异的机械性能等, 在电化学储 能、吸附、催化以及传感等领域有着极为重要的应用。本文从石墨烯气凝胶的结构设计与组装策略出发, 综 述了近年来石墨烯纳米结构单元在石墨烯气凝胶材料(氧化石墨烯、还原氧化石墨烯、化学气相沉积(CVD)石 墨烯、以及复合气凝胶等)中的组装行为, 并对石墨烯气凝胶目前的现状及今后发展方向做了简要评述。
\end{abstract}

关键词: 石墨烯; 气凝胶; 水凝胶; 复合材料; 组装 中图分类号: 0648

\section{Controlled Assembly of Graphene-Based Aerogels}

\author{
LI Guang-Yong ${ }^{1,2} \quad$ WU Xiao-Han ${ }^{2} \quad$ HE Wei-Na ${ }^{2} \quad$ FANG Jian-Hui ${ }^{1, *} \quad$ ZHANG Xue-Tong ${ }^{2, *}$ \\ ('Department of Chemistry, College of Sciences, Shanghai University, Shanghai 200444, P. R. China; \\ ${ }^{2}$ Suzhou Institute of Nano-tech and Nano-bionics, Chinese Academy of Sciences, Suzhou 215123, Jiangsu Province, P. R. China)
}

\begin{abstract}
Graphene aerogels are obtained from graphene sheets through wet chemical assembly or vaporphase chemical growth. They have a three dimensional graphene architecture that has an interconnected network with a high specific surface area, good electric conductivity and other physicochemical properties and thus has important applications in electrochemical energy storage, adsorption, catalysis and sensing. In this review, we will highlight the assembly strategies and structural designs used to introduce the controlled assembly of the graphene sheets in graphene aerogel materials, such as graphene oxide-, reduced graphene oxide-, CVDgrown graphene and composite graphene aerogels. The current challenges and future development of the grapheme aerogels are also discussed.
\end{abstract}

Key Words: Graphene; Aerogel; Hydrogel; Composite material; Assemble

\section{1 引言}

石墨烯 ${ }^{1}$, 单层碳原子组成的六边蜂巢二维晶 体, 是迄今为止最薄的材料, 厚度仅有 $0.35 \mathrm{~nm}$, 是其他维度石墨材料的基本组成单元 ${ }^{2,3}$ 。石墨烯的 每个碳原子均具有 $s p^{2}$ 杂化结构 ${ }^{2}$, 在同一平面上通 过三个很强的 $\sigma$ 键与相邻三个碳原子相连, 形成正
六边形的环, 伸展成片层结构, 同时贡献出一个 $p$ 轨道上的电子, 形成大 $\pi$ 键网络, 从而使得 $\pi$ 电子 在石墨烯表面上可以自由移动。其独特的结构赋 予石墨烯优异的电学、力学、热学、光学等性 能, 例如具有良好的导热性 $\left(5000 \mathrm{~W} \cdot(\mathrm{m} \cdot \mathrm{K})^{-1}\right)^{4}$ 、超 高的比表面积 $\left(2630 \mathrm{~m}^{2} \cdot \mathrm{g}^{-1}\right)^{5}$ 、高达 $10^{13} \mathrm{~cm}^{-2}$ 的载流

Received: April 11, 2016; Revised: May 23, 2016; Published online: May 24, 2016.

*Corresponding authors. ZHANG Xue-Tong, Email: zhangxtchina@yahoo.com; Tel: +86-512-62872821. FANG Jian-Hui, Email: jhfang@shu.edu.cn; Tel: +86-21-66132663.

The project was supported by the National Natural Science Foundation of China $(51572285,21373024,21404117)$.

国家自然科学基金(51572285, 21373024, 21404117)资助项目

(c) Editorial office of Acta Physico-Chimica Sinica 
子密度以及超高的电子迁移率 $\left(200000 \mathrm{~cm}^{2} \cdot(\mathrm{V} \cdot\right.$ $\left.\mathrm{s})^{-1}\right)^{6}$ 。然而, 本征石墨烯展现出的化学惰性、难分 散, 片层间的 $\pi-\pi$ 相互作用以及范德华作用促使 石墨烯发生不可逆凝聚, 这成为石墨烯二维材料 在某些领域应用的巨大障碍。

近年来, 操纵石墨烯组装为具有不同维度 $(一$ 维、二维、三维)的宏观体材料 ${ }^{7-11}$, 成为石墨烯最 为重要的研究方向之一。其中经特定组装方式获 得三维石墨烯材料, 并能够最大程度上展现石墨 烯二维片层的性质，对于扩展石墨烯宏观材料应 用具有重要意义 $7,9,12,13$ 。

石墨烯气凝胶就是一种典型的三维石墨烯材 料, 是一种具有高比表面积、高孔隙率、良好的 导电与导热性以及优异机械强度的新型纳米功能 材料, 在能源存储与转换、催化、吸附及传感等 领域受到广泛关注。本文综述了石墨烯片层单元 在石墨烯气凝胶材料(氧化石墨烯气凝胶、还原氧 化石墨烯气凝胶、化学气相沉积石墨烯气凝胶及

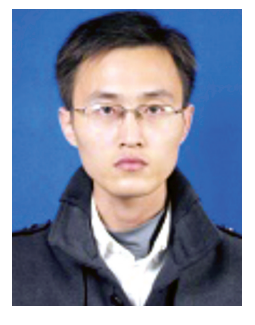

李广勇，1990年生。2013年本科毕 业于青岛科技大学材料学院, 随后 在上海大学方建慧教授与中国科学 院苏州纳米所张学同研究员的共同 指导下攻读硕士学位。研究方向为 石墨烯气凝胶可控组装及性能研究。
复合气凝胶与元素掺杂气凝胶)制备中的组装行 为, 并对石墨烯气凝胶的发展做了展望。

\section{2 氧化石墨烯气凝胶}

氧化石墨烯 $(\mathrm{GO})$ 是化学还原或热还原制备石 墨烯时的中间产物，是被深度氧化的石墨烯，一 般经由氧化石墨在液相中超声剥离获得 ${ }^{14-17}$ 。GO 具有丰富的含氧官能团：分布于碳原子层基平面 上的羟基和环氧基团; 悬挂于碳原子层边缘的羰 基和羧基基团。氧化石墨烯所具有的含氧官能团 赋予其良好的水溶性, 同时, 边缘所悬挂的羧酸基 团提供足够的静电平衡使氧化石墨烯在水溶液中长 期稳定存在。而通过调控 GO 片层的水合作用与静 电作用力, 可实现 $\mathrm{GO}$ 片层的交联、搭接, 组装成 为 $\mathrm{GO}$ 水凝胶, 并进一步实现 $\mathrm{GO}$ 气凝胶的制备。

目前, $\mathrm{GO}$ 水凝胶的制备归纳起来有如下方 法: (1) 聚合物交联法。采用的聚合物如可通过分 子链捆绑、氢键针定的聚乙烯醇等 ${ }^{18}$, 可调控 $\mathrm{GO}$ 片层间静电作用力的聚二烯丙基二甲基氯化铵或 聚乙烯亚胺 ${ }^{7}$, 可调控氢键、疏水作用及静电斥力 三者之间微妙平衡的 DNA 及血清蛋白等生物高分 子 19,20 等。(2) 小分子促进剂法。采用的小分子促进 剂如季铵盐十六烷基三甲基溴化铵、金属离子 等 7,21 , 可通过静电引力约束、绑定 $\mathrm{GO}$ 片层, 实现 GO 片层组装与凝胶化。(3) 无交联剂法。如引入 盐酸, 降低体系 $\mathrm{pH}$ 值以破坏静电平衡实现 $\mathrm{GO}$ 片

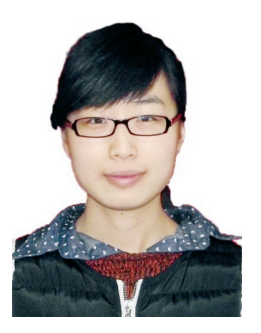

吴晓涵，1991 年生。2013 年本科 毕业于青岛科技大学材料学院, 2015 年硕士毕业于青岛科技大学材 料学院, 目前在中国科学院苏州纳 米所张学同研究员的指导下攻读博 士学位。研究方向主要为新型石墨 烯气凝胶的可控制备及性能研究。

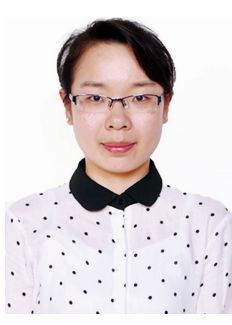

何伟娜，1986 年生。2013 年博士 毕业于浙江大学，2013-2015 年于 中国科学院苏州纳米所从事博士后 研究。现为上海交通大学医学院讲 师。主要从事导电高分子的合成和 自组装、医用/药用高分子材料等 方面的基础研究。

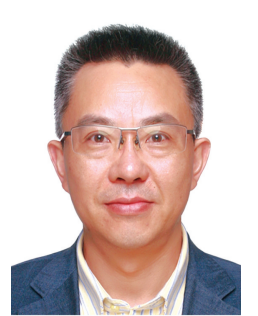

方建慧, 1966 年生。1986 年本科 毕业于浙江大学, 1994 年硕士毕 业于上海科技大学, 2006 年博士 毕业于上海大学。上海大学理学院 副院长、教授、博导, 中国化学会 理事, 上海市化学化工学会理事。

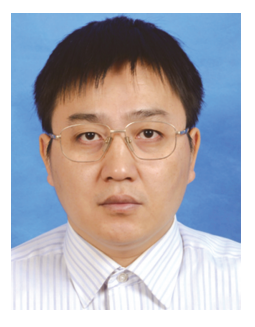

张学同, 北京理工大学博士; 北京 大学博士后; 英国约克大学等研究 助理; 2008 年加入北京理工大学, 先后担任教授、博士生导师; 2013 年加入中国科学院苏州纳米所, 任 “百人计划” 研究员、博士生导 师、研究部副主任等职务。 
层的组装与凝胶化 ${ }^{7}$ 。然而, 在 $\mathrm{GO}$ 溶液中直接引 入交联剂或酸, 常触发快速凝胶动力学过程, 使 得 $\mathrm{GO}$ 凝胶化过程难以控制, 造成 $\mathrm{GO}$ 水凝胶的微 观结构不均匀, 进而导致凝胶网络结构的稳定性 不足以支撑气凝胶的制备。

Zhang 小组 ${ }^{22}$ 对 GO 的凝胶过程进行优化, 在 $\mathrm{GO}$ 分散系中引入 $\mathrm{pH}$ 调节剂(葡萄糖酸内酯, GDL), 通过 GDL 的缓慢水解, 逐步降低体系 $\mathrm{pH}$ 值, 同时原位缓慢释放多价金属离子或多胺的质 子化, 实现结构稳定、均匀的 GO 水凝胶的制备: 首先将 $\mathrm{GO}$ 分散液调成碱性 $(\mathrm{pH}=8)$, 随后依次引 入金属氢氧化物或聚乙烯亚胺, 室温静置 $24 \mathrm{~h}$, 获 得可用来制备气凝胶的 $\mathrm{GO}$ 水凝胶。

氧化石墨烯气凝胶是通过超临界干燥或冷冻 干燥技术，在保持凝胶网络不被破坏的前提下， 将氧化石墨烯湿凝胶中的溶剂分子置换成气体, 最终获得具有低密度、高比表面积、高孔隙率的 气凝胶材料。其中超临界干燥技术, 是利用超临 界二氧化碳 $\left(\mathrm{Sc} \mathrm{CO}_{2}\right)$ 置换出凝胶中溶剂分子的干燥 过程, 理论上不会改变凝胶网络结构; 而冷冻干 燥过程中, 冰晶的诱导效应会在原有凝胶网络中 引入宏孔结构, 但最终获得的气凝胶亦具有连通 的多孔网络结构。Zhang 小组 ${ }^{23}$ 利用氧化石墨烯片 层与金属离子/质子化多胺分子间的强静电相互作 用, 实现 GO边对边(edge-to-edge)三维自组装, 通 过 $\mathrm{Sc} \mathrm{CO}_{2}$ 干燥制备出具有高比表面积 $\left(854 \mathrm{~m}^{2}\right.$. $\left.\mathrm{g}^{-1}\right)$ 、高机械强度( $\left.10 \mathrm{MPa}\right) 、$ 高化学活性(可有效 吸附 $\mathrm{H}_{2} \mathrm{~S} 、 \mathrm{SO}_{2} 、 \mathrm{HI} 、 \mathrm{CO}$ 等还原性气体) 的 $\mathrm{GO}$ 气凝 胶, 实现了气凝胶中石墨烯片层的边对边组装, 极为有效地降低了 $\mathrm{GO}$ 三维自组装过程中的 $\pi-\pi$ 堆 垛效应。通过调控凝胶动力学过程, 实现了结构 均匀、性能优异的氧化石墨烯气凝胶的制备, 但 上述凝胶化组装均基于氧化石墨烯溶液, GO 片层 随机搭接进而凝胶化, 无法调控 GO片层有序、规 整组装。

氧化石墨烯液晶实现了石墨烯片层的液相有 序排列, 是制备高性能石墨烯宏观体材料所选用 的最佳前驱体。Gao 小组 ${ }^{24}$ 利用液晶的有序取向以 及冰晶诱导效应, 直接冷冻干燥高浓度氧化石墨 烯液晶, 获得具有规整微观结构的 $\mathrm{GO}$ 气凝胶, 其 开放的规整结构作为理想的催化剂载体, 为催化 剂提供 “纳米笼效应”, 并在 $\mathrm{S} \rightarrow \mathrm{O}$ 乙酰基迁移反 应中表现出超快的催化速率(5-8h)、高的催化选

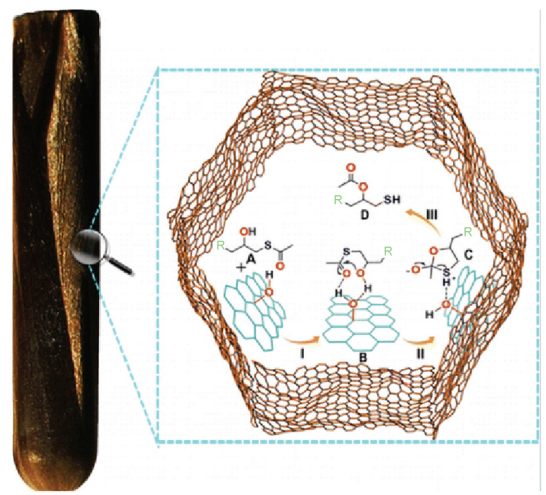

图 1 GO 气凝胶光学照片及其用于催化剂容器的结构模型 ${ }^{24}$

Fig.1 Photograph and the structure module of graphene oxide (GO) aerogel catalytic reactor derived from GO liquid crysta ${ }^{24}$

择性(100\%)及高的产率( 100\%)等优点, 如图 1 所 示。其中液晶与冰晶诱导技术的结合, 为实现 $\mathrm{GO}$ 气凝胶无序孔结构向有序孔结构的转变提供可 能。但如何实现高浓度氧化石墨烯液晶体系中片 层的原位凝胶化, 则尚未见报道。

\section{3 还原氧化石墨烯气凝胶}

还原氧化石墨烯( $(\mathrm{rOO})$, 是 $\mathrm{GO}$ 经过还原处理 (消除含氧官能团、恢复石墨烯的二维共轭结构)后 所获得的产物, 又常称之为石墨烯 (graphene)。其 中常用的还原方法有水热还原、溶剂热还原、化 学还原、电化学还原及高温热处理等。值得注意 的是, 由于选用还原方法的不同, 所获得的石墨 烯展现出的 $\mathrm{C} / \mathrm{O}$ 原子比及化学组成亦存在差异, 故 在提及到 $\mathrm{rGO}$ 时, 常需注明所选用的还原方法或 还原剂种类。

还原氧化石墨烯气凝胶的组装包括石墨烯水 凝胶前驱体的组装及特殊的干燥工艺。首先通过 消除 GO片层上的含氧官能团, GO片层开始向石 墨烯片层转变, 同时伴随着片层共轭结构的恢 复、片层疏水性增加及静电平衡的削弱等, 导致 石墨烯片层相互搭接、堆垛, 获得具有三维多孔 (纳米级、微米级)网络结构的石墨烯宏观聚集态, 即石墨烯水凝胶。其次利用特定的干燥方法, 如 超临界流体干燥、冷冻干燥及常压干燥, 在维持 三维多孔网络完好的状态下, 将溶剂分子以气体 分子取代, 获得的干凝胶即石墨烯气凝胶。

\section{1 石墨烯水凝胶前驱体}

目前, 按照氧化石墨烯还原条件的不同, 石 墨烯水凝胶前驱体的制备可分为水热组装、化学 
还原组装、电化学还原组装及金属还原组装。

\section{1 .1 水热组装}

水热组装是在高温、高压环境下, $\mathrm{GO}$ 在水溶 液中进行含氧官能团消除, 共轭结构恢复, 伴随 着疏水作用的增强及静电平衡破坏等, 石墨烯片 层相互搭接、组装并获得石墨烯水凝胶。

Shi 小组 ${ }^{25}$ 采用简易的水热法首次合成全石墨 烯水凝胶： $\mathrm{GO}$ 溶液于 $180^{\circ} \mathrm{C}$ 环境下水热处理 12 $\mathrm{h}$, 经自组装形成三维网络结构(图 2c), 获得具有 高导电性 $\left(0.5 \mathrm{~S} \cdot \mathrm{m}^{-1}\right)$ 、高弹性模量 $(0.29 \mathrm{MPa})$ 以及 高屈服强度 $(24 \mathrm{kPa})$ 的块体石墨烯水凝胶 $(\mathrm{SGH})$, 如图 2(a,b) 所示, 是性能优异的超级电容器固体电 极材料, 并可直接应用于超级电容器的制备。随 后该小组 ${ }^{26}$ 采用水合肼或氢碘酸对其进一步还原处 理, 赋予处理后的水凝胶以更高的导电性(1.3-3.2 $\left.\mathrm{S} \cdot \mathrm{m}^{-1}\right)$ 以及更为优异的电化学行为 $\left(220 \mathrm{~F} \cdot \mathrm{g}^{-1}\right)$ 。

为了进一步揭示水热组装对石墨烯水凝胶结 构、形貌与超级电容性能的影响, 研究者们针对 反应温度以及 $\mathrm{GO}$ 溶液的浓度与 $\mathrm{pH}$ 值等因素进行 了系统研究 ${ }^{27}$, 发现随着反应温度的提高, 时间的 延长, 所获得水凝胶的机械强度及电化学性能均 有很大提高, 为优化石墨烯宏观材料的性能提供 支持。近期, Cerruti 小组 ${ }^{28}$ 研究了氧化石墨烯水热 凝胶化过程中的化学反应历程以及对水热反应产 物进行量化。首次对氧化石墨烯的水热反应中所 产生大量的 $\mathrm{CO}_{2}$ 、有机酸碎片以及 $\mathrm{CO}$ 进行精确量 化、评估, 并通过滴加氨水将 $\mathrm{CO}_{2}$ 转换为离子基 团, 为制备高强度、高导电性的无气孔石墨烯水 凝胶提供理论指导。

水热还原方法操作简便, 无粘结剂、化学添 加剂的使用, 避免了非碳类杂质的引入, 同时亦
避免了后续繁杂的去除添加剂的处理。但该方法 的反应环境苛刻, 在一定程度上限制了石墨烯水/ 气凝胶的合成与应用。

\section{1 .2 化学还原组装}

化学还原组装是比水热组装更为温和的一种 石墨烯水凝胶的制备方法。选取合适的、温和的 化学还原剂, 将其溶于 $\mathrm{GO}$ 水溶液中, 室温或水浴 加热静置, 获得结构均匀、稳定的石墨烯水凝胶。

维生素 $\mathrm{C}$ 作为一种绿色、温和的还原剂, 不同 于水合肼、硼氢化钠和 $\mathrm{LiAlH}_{4}$ 等在还原时会产生 气体, 维生素 $\mathrm{C}$ 在还原氧化石墨烯过程中无气体产 生, 最先见于石墨烯水凝胶的化学还原组装。 Zhang 小组 ${ }^{29}$ 在 $\mathrm{GO}$ 溶液中引入维生素 $\mathrm{C}$, 水浴静 置, 获得结构均匀、稳定的石墨烯水凝胶, 并系 统研究了 $\mathrm{GO}$ 浓度、 $\mathrm{pH}$ 值、维生素 $\mathrm{C}$ 用量以及反 应温度、反应时间等因素对石墨烯水凝胶的影 响, 发现当 $\mathrm{GO}$ 浓度小于 $1.0 \mathrm{mg} \cdot \mathrm{mL}^{-1}$ 时不易凝 胶, 当大于 $6.0 \mathrm{mg} \cdot \mathrm{mL}^{-1}$ 时则会存在溶液不易均匀 分散的问题; 由此选取 $4.0 \mathrm{mg} \cdot \mathrm{mL}^{-1}$ 的 $\mathrm{GO}$ 分散液 进一步分析, 发现凝胶时间随维生素 $\mathrm{C}$ 用量的增 加、反应温度的升高和 $\mathrm{pH}$ 值的减小而减小, 为实 现石墨烯在温和的环境中进行三维组装提供新的 研究思路。Yan 小组 ${ }^{30}$ 采用 $\mathrm{NaHSO}_{3} 、 \mathrm{Na}_{2} \mathrm{~S} 、 \mathrm{HI}$ 、对 苯二酚等为还原剂, 进一步解释石墨烯水凝胶的 化学还原组装机理, 通过改变反应容器的大小与 形状实现了对水凝胶尺寸与形状的控制。此外，抗 坏血酸钠 ${ }^{31} 、 \mathrm{Sn}^{2+} 32 、 \mathrm{Fe}^{2+} 33$ 、多巴胺 ${ }^{34}$ 、水合肼 ${ }^{35} 、$ 草酸和 $\mathrm{NaI}^{36}$ 、次磷碘酸 ${ }^{37}$ 等其他还原剂以类似的原 理被应用于石墨烯水凝胶材料的组装制备中。

\subsection{3电化学还原组装}

电化学还原组装是一种典型的固-液界面组
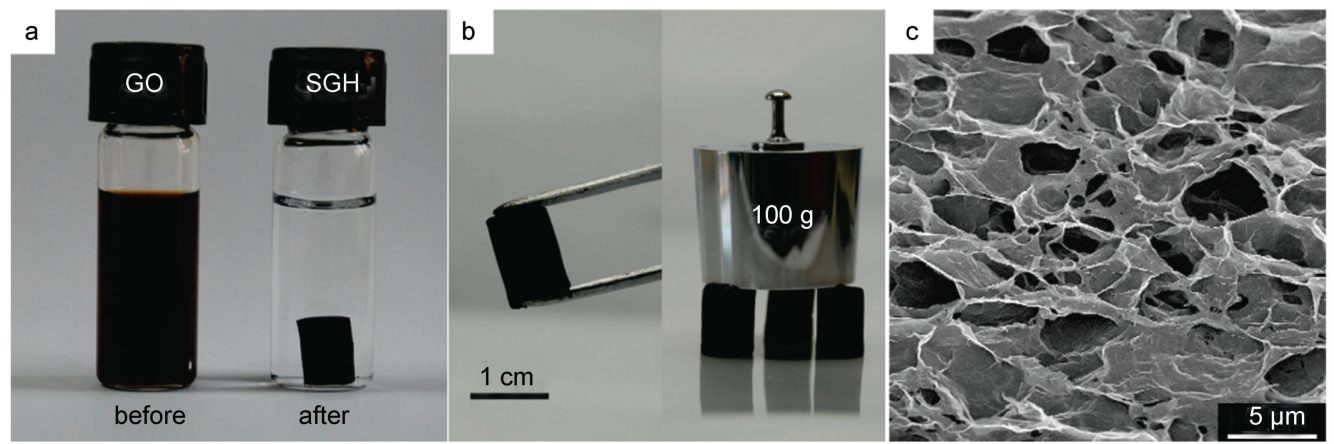

图 2 氧化石墨烯水热处理前后(a)、水热合成的自组装石墨烯水凝胶(SGH)的光学照片(b)及其微观扫描电镜(SEM)图片(c) $)^{25}$

Fig.2 Photographs of homogeneous GO aqueous dispersion before and after hydrothermal reduction (a), photographs of a strong self-assembled graphene hydrogel (SGH) (b), and scanning electron microscopy (SEM) images of the SGH interior microstructures $\left(c^{25}\right.$ 
装, 具有速度快、简便、易控等优点, 并可实现 在电极材料表面直接沉积获得石墨烯三维凝胶网 络, 可直接应用于电化学器件。

通过电化学还原获得的石墨烯具有更强的疏 水性以及更强的 $\pi-\pi$ 堆积取向, 促使其在电极表 面的沉积, 并获得垂直于电极表面的石墨烯三 维网络。 $\mathrm{Shi}$ 小组 ${ }^{38}$ 通过电解 $\mathrm{GO}\left(3.0 \mathrm{mg} \cdot \mathrm{mL}^{-1}\right)$ 与 $\mathrm{LiClO}_{4}\left(0.10 \mathrm{~mol} \cdot \mathrm{L}^{-1}\right)$ 的分散液一步实现 $\mathrm{GO}$ 在电极 表面(金䈃)的还原组装, 获得具有三维连通结构的 石墨烯基电极, 该电极材料表现出优异的倍率性 能( $120 \mathrm{~Hz}$ 时, 表现出 $-84^{\circ}$ 的相位角), 有望替换铝 电极电容器并应用于交流线性滤波器中。随后, 该小组 ${ }^{39}$ 成功在 $\mathrm{Au}$ 纳米线上实现石墨烯的三维自 组装, 并获得性能优异的、可编织的柔性纤维状 电化学电容器。

\section{1 .4 金属还原组装}

活性金属具有一定的还原性, 酸性环境下可 发生氧化还原反应, 在固-液界面具有电子转移现 象, 而 GO 具有丰富的含氧官能团, 具有高的化学 活性。将活性金属浸入至具有一定 $\mathrm{pH}$ 值的 $\mathrm{GO}$ 溶 液中, 可使得电子在金属与 $\mathrm{GO}$ 之间进行转移, 并 获得性能独特的石墨烯材料。早在石墨烯纸以及薄 膜材料的研究中, 已有关于铝篞表面 ${ }^{4}$ 实现 GO 自 组装的报道，同时在惰性金属、半导体 $\mathrm{Si}$ 、碳基材 料以及 ITO 玻璃表面的自组装亦被系统报道 ${ }^{41}$ 。

$\mathrm{Kim}$ 小组 ${ }^{42}$ 将 $\mathrm{Zn}$ 䈃浸入弱酸性的 $\mathrm{GO}$ 溶液中, 在其表面实现 $\mathrm{GO}$ 的自发还原与组装, 如图 3 所 示, 获得具有优异性能的石墨烯水/气凝胶薄膜以 及复合石墨烯水凝胶纺布。该水凝胶薄膜表现出 高的比表面积 $\left(614.9 \mathrm{~m}^{2} \cdot \mathrm{g}^{-1}\right.$, 通过亚甲基蓝吸附测 定), 并可承受 $0.9 \mathrm{MPa}$ 的应力; 在超级电容器性 能测试中, 展现出优异的快速充放电性能 $(10 \mathrm{~mA}$. $\mathrm{cm}^{-2}$ 速率下, 在循环 4000 次后, 可保持 $97.8 \%$ 的初
始比电容)。

\section{2 还原氧化石墨烯气凝胶干燥}

在制备石墨烯气凝胶时, 研究者们往往是在 上述石墨烯水凝胶制备的基础上, 针对性的选择 合适的干燥方式对石墨烯水凝胶进行干燥, 获得 石墨烯气凝胶。目前常用的干燥方式有超临界干 燥、冷冻干燥, 而作为最为简便、能耗最低的石 墨烯气凝胶常压干燥技术尚不成熟。

\subsection{1 超临界干燥}

超临界干燥方法可将凝胶中的溶剂分子全部 替换为气体分子, 同时保持三维多孔网络不被破 坏, 获得石墨烯气凝胶。该方法可将石墨烯水凝 胶的网络完美呈现在气凝胶中, 所获得气凝胶具 有高的机械强度、高的比表面积, 并表现出优异 的超级电容行为。

Zhang 小组 ${ }^{43}$ 以抗坏血酸为还原剂, 实现氧化 石墨烯的溶胶-凝胶转变, 获得结构均匀的石墨烯 水凝胶前驱体, 随后经 $\mathrm{Sc} \mathrm{CO}_{2}$ 干燥制备得到高比 表面积 $\left(512 \mathrm{~m}^{2} \cdot \mathrm{g}^{-1}\right)$ 、高导电性 $\left(\sim 100 \mathrm{~S} \cdot \mathrm{m}^{-1}\right)$, 优异 的机械性能(可支撑起自身 14000 倍重压)及高比电 容 $\left(128 \mathrm{~F} \cdot \mathrm{g}^{-1}\right)$ 的石墨烯气凝胶, 是高性能超级电容 器电极材料。如图 4 所示。

Duong 小组 ${ }^{44}$ 对水热还原的石墨烯水凝胶进行 $\mathrm{Sc} \mathrm{CO}_{2}$ 干燥获得石墨烯气凝胶, 并系统研究了 $\mathrm{GO}$ 溶液浓度、水热时间等因素对石墨烯气凝胶的组 装及性能的影响, 发现气凝胶的比表面积和孔容 随 GO 浓度的提高而增大, 随着水热时间的延长而 减小, 同时密度亦会增加, 为优化石墨烯组装策 略及性能展现提供理论支撑。

Xing 小组 ${ }^{45}$ 采用超临界干燥方式将组装与还原 过程分离: 首先低温水热实现 $\mathrm{GO}$ 的三维组装, 经 超临界干燥获得 $\mathrm{GO}$ 气凝胶, 随后经 $\mathrm{H}_{2}$ 还原获得具 有高比表面积 $\left(870 \mathrm{~m}^{2} \cdot \mathrm{g}^{-1}\right)$ 、高 $\mathrm{C} / \mathrm{O}$ 原子比(69.9)及

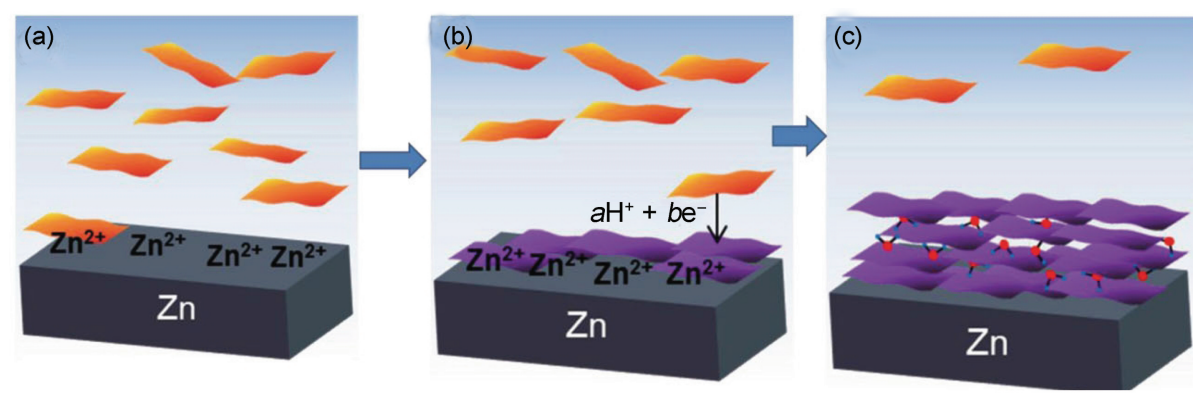

图 3 金属表面石墨烯凝胶化机理示意图 ${ }^{42}$

Fig.3 Schematic illustration of graphene gelation mechanism on metal surface ${ }^{42}$ 
(a)

(b)

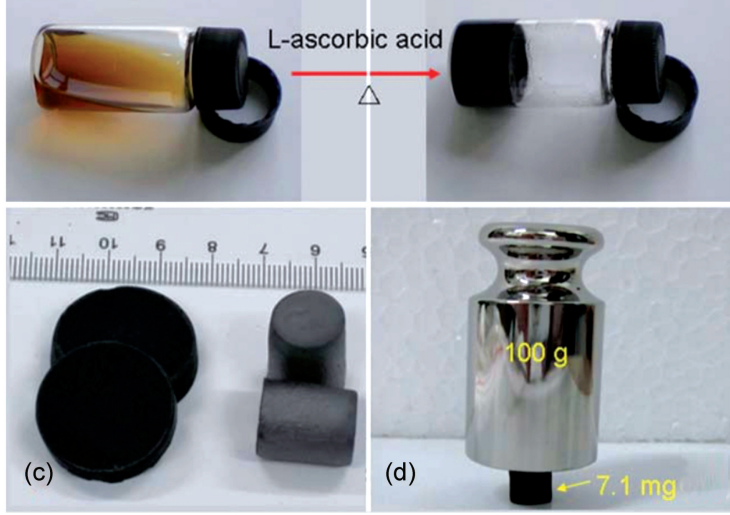

图 4 GO 分散液(a), 石墨烯水凝胶(b)及其超临界 $\mathrm{CO}_{2}$ 干 燥(左)与冷冻干燥(右)获得的气凝胶实物图片(c)以及能够 支撑自身 14000 倍重物的气凝胶 $(d)^{43}$

Fig.4 Digital photos of the aqueous suspension of GO (a), the graphene hydrogel (b), the supercritical $\mathrm{CO}_{2}$ dried (left) and freeze-dried (right) graphene aerogel (c), and graphene aerogel pillar supporting a counterpoise, more than 14000 times its own weight $(d)^{43}$

高导电性的 $\mathrm{rGO}$ 气凝胶, 在超级电容器应用中展 现出高倍率性能, 同时该组装策略有效降低石墨 烯片层的 $\pi-\pi$ 堆垛效应, 并揭示氧化石墨烯中含 氧官能团间的氢键相互作用引起的自组装机理。

\section{2 .2 冷冻干燥}

冷冻干燥又称升华干燥, 将水凝胶冷冻到冰 点以下, 进行冰晶诱导生长, 使水转变为冰, 然 后在较高真空下使冰升华, 最终以空气取代冰 晶, 获得具有三维多孔网络的石墨烯气凝胶。

为避免冷冻干燥过程中真空环境对石墨烯片 层网络结构的破坏, 石墨烯网络需要具有一定的 稳定性。对此, 研究者们常采用金属离子辅助、 聚合物涂层固化以及优化凝胶组装过程获得稳定 的三维网络结构。Wang 小组 ${ }^{46}$ 在低温水热环境 中, 采用贵金属离子辅助 $\mathrm{GO}$ 片层还原组装同时实 现对片层网络结构进行稳定, 经冷冻干燥, 获得 结构可调并具有优异机械性能、高导电性的石墨 烯气凝胶材料, 同时该气凝胶材料作为催化剂载 体, 在 Heck 反应中展现出高的催化活性以及选择 性; 此外石墨烯片层间的少量贵金属颗粒避免了 石墨烯片层的面与面重排聚集。 $\mathrm{Ma}$ 小组 ${ }^{47}$ 在低温 水热环境下利用非贵金属离子 $\left(\mathrm{Ca}^{2+} 、 \mathrm{Ni}^{2+} 、 \mathrm{Co}^{2+}\right)$ 对 GO 进行组装, 经聚乙烯醇(PVA) 固化、冷冻、 干燥获得具有三维多孔结构的石墨烯气凝胶。 Gao 小组 ${ }^{48}$ 一步实现颈基乙酸对氧化石墨烯的还
原与自组装以及石墨烯的改性, 经冷冻干燥获得 具有高孔隙率 $(\sim 96 \%)$ 、高强度并对 $\mathrm{Cu}^{2+} 、 \mathrm{Cd}^{2+}$ 、 $\mathrm{Pb}^{2+}$ 等金属离子具有较强吸附能力的石墨烯气凝 胶。

宏孔结构是赋予石墨烯气凝胶高弹性的前 提, 引入乳液模板或冰晶诱导, 可实现孔结构的 调控, 获得宏孔石墨烯气凝胶。研究者们利用氧 化石墨烯的双亲性, 在氧化石墨烯溶液中引入油 相液滴, 可获得均匀、稳定的乳液体系, 经高温 水热处理及冷冻干燥, 可获得轻质、高弹性石墨 烯气凝胶 ${ }^{49-51}$, 如图 5 所示。

Zhao 小组 ${ }^{52}$ 以乙二胺为还原剂和空间位阻剂, 实现对氧化石墨烯的功能化还原与组装, 经冷冻 干燥以及微波辐射处理获得可压缩的石墨烯气凝 胶材料，该材料在被压缩 $90 \%$ 后可无损恢复至初 始状态。 $\mathrm{Li}$ 小组 ${ }^{53}$ 在石墨烯水凝胶制备过程中引入 两次冰晶诱导生长, 经由冷冻干燥获得具有蜂巢 状三维多孔网络结构的石墨烯气凝胶弹性体, 该 气凝胶表现出超快的动态压阻效应以及高的灵敏 度，是一种性能优异的应力传感材料。

此外, 冷冻干燥过程中的冰晶诱导效应可对 石墨烯三维网络进行二次 “组装”, 获得具有规整 孔结构的气凝胶材料。Gao 小组 ${ }^{54}$ 对氧化石墨烯液 晶进行取向处理及冰晶诱导组装, 冷冻干燥后经 化学还原、高温退火获得具有整齐孔洞结构的石 墨稀气凝胶纤维, 纤维断面如图6所示, 具有独特 的圆柱形、多孔、核壳组合结构以及良好的机械/ 导电性。

冰晶的诱导效应会在一定程度上改变凝胶网 络结构, 对所得气凝胶的比表面积、机械强度等

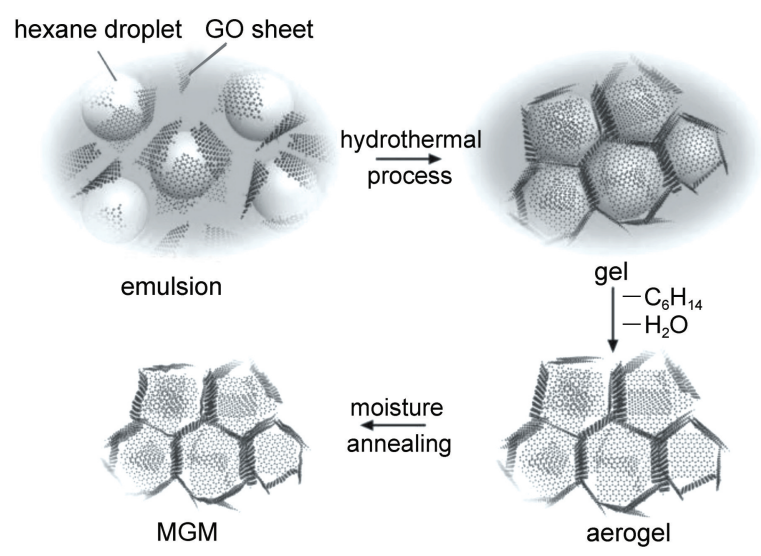

图 5 大孔石墨烯宏观体的制备示意图 ${ }^{49}$

Fig.5 Schematic illustration of the preparation of macroporous graphene monoliths (MGM) ${ }^{49}$ 


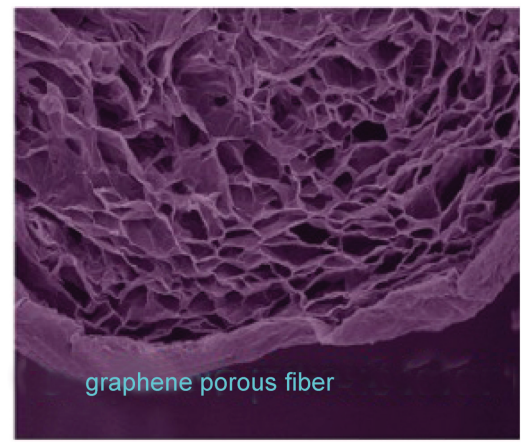

图 6 还原石墨烯气凝胶纤维断面 SEM 图片 ${ }^{54}$

Fig.6 SEM image of the fracture morphology of reduced graphene porous fiber ${ }^{54}$

性能造成损失。但却会赋予气凝胶优异的可压缩 弹性性能、三维多孔网络结构的二次设计可行 性, 这是超临界干燥所不能做到的。

\section{2 .3 常压干燥}

Zhang 小组 ${ }^{5}$ 在原有石墨烯水凝胶的基础上, 引入两次冷冻与解冻过程, 实现了石墨烯气凝胶 的常压干燥：氧化石墨烯溶液经过初步凝胶过 程、冷冻解冻、二次凝胶、冷冻解冻, 获得目标 水凝胶, 随后于 $60{ }^{\circ} \mathrm{C}$ 烘箱干燥 $24 \mathrm{~h}$, 获得超弹性 (压缩应变大于 $90 \%$ 时, 可快速恢复至初始状态)石 墨烯气凝胶。

相比于冷冻干燥、超临界干燥, 常压干燥具 有能耗低、操作简便、生产周期短等优点。但目 前常压干燥获得的石墨烯气凝胶的孔径达到几百 微米, 且几乎无比表面积, 尚不能满足气凝胶的 性能要求, 故常压干燥还有较长的路要走。

\section{4 化学气相沉积石墨烯气凝胶}

化学气相沉积法 $(C V D)^{56-61}$ 是制备高质量石墨 烯薄膜材料的主要方法。采用具有三维多孔网络 结构的基底材料替换原先的二维平面基底材料,
可实现石墨烯的三维生长, 获得石墨烯泡沫/气凝 胶材料。该材料具有高的比表面积、优异的导电 性以及完美的无缝连接三维网络多孔结构, 展现 出更接近于本征石墨烯的性能。

中国科学院沈阳金属研究所 Cheng 小组 ${ }^{62}$ 以镍 泡沫为模板, $\mathrm{CH}_{4}$ 为碳源, 在镍泡沫上进行石墨烯 的生长, 获得具有宏观 3D 形态的石墨烯泡沫。随 后, Chen 小组 ${ }^{63}$ 以乙醇为碳源, 于常压下实现石墨 烯在镍泡沫基底上的 $3 \mathrm{D}$ 生长, 获得具有柔性、导 电、独立支撑的微生物燃料电池的块体电极(阳极) 材料。 $\mathrm{Liu}$ 小组 ${ }^{64}$ 选用 $\mathrm{NiCl}_{2} \cdot 6 \mathrm{H}_{2} \mathrm{O}$ 为催化剂前驱 体, 采用 CVD 方法实现了高密度、高质量三维石 墨烯宏观体的常压制备, 克服了常规泡沫镍-三维 石墨烯孔隙率高、密度低、机械性能弱等缺点。 然而, 上述 $\mathrm{CVD}$ 生长的 $3 \mathrm{D}$ 石墨烯由于受基底孔尺 寸限制, 其孔径分布均为宏孔, 故常称之为 “石 墨烯泡沫”。

近期, Huang 小组 ${ }^{65}$ 选用 $\mathrm{SiO}_{2}$ 气凝胶为基底, 以 $\mathrm{CH}_{4}$ 为碳源, 制备出具有四面连通 “空心管状” 微观孔结构的超轻石墨烯气凝胶超材料。该材料 表现出高孔隙率(99.9\%)、不可毁灭(火、化学药 品)、轻质、类金属导体以及超乎寻常的机械强 度、刚度与完整的形状记忆特性等优异的理化性 能。随后, 该小组 ${ }^{66}$ 通过改变基底材料, 获得具 有 “介孔石墨烯填充管状” 微观孔结构的石墨烯 气凝胶材料，如图 7 所示。该材料具有高比表面 积 $\left(1591 \mathrm{~m}^{2} \cdot \mathrm{g}^{-1}\right)$ 、高孔容 $\left(\sim 2.62 \mathrm{~cm}^{3} \cdot \mathrm{g}^{-1}\right)$ 、高导电 率 $\left(32.5 \mathrm{~S} \cdot \mathrm{cm}^{-1}\right)$, 在电化学储能中展现出高比电容 $\left(\sim 303 \mathrm{~F} \cdot \mathrm{g}^{-1}\right)$ 、优异的循环稳定性等。以氧化硅气 凝胶为基底, 用于石墨烯的三维生长中, 弥补了 前期泡沫镍基底带来的低比表面积、弱机械强度 等缺点, 对研究本征石墨烯的电化学行为以及电 化学能源存储等具有重要的指导作用。
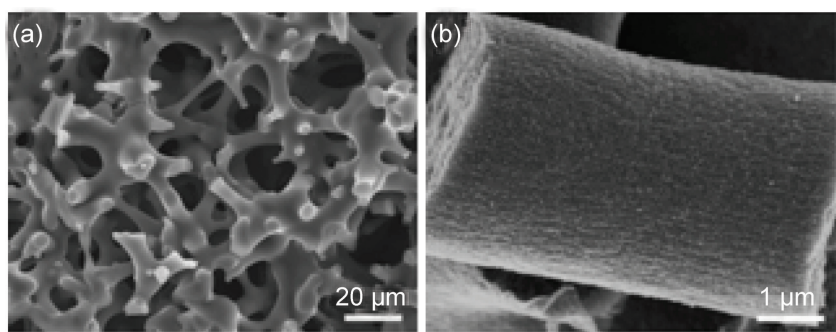
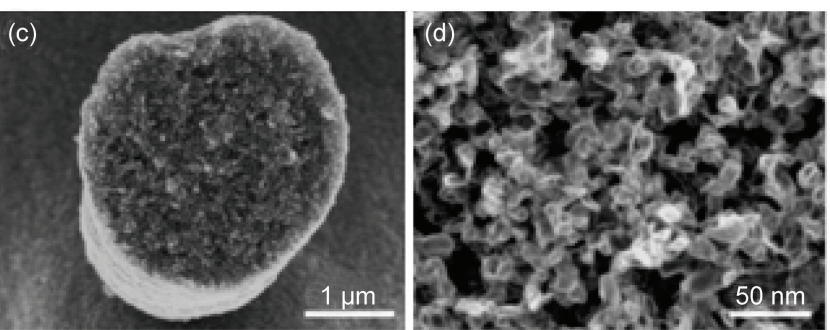

图 7 CVD 石墨烯气凝胶的 SEM 图片 ${ }^{66}$

Fig.7 SEM images of CVD graphene aerogel ${ }^{66}$

(a) low magnification SEM image of CVD graphene aerogel; (b, c) surface and cross-section SEM image of an individual microrod;

(d) high magnification SEM image of an individual microrod 


\section{5 石墨烯复合气凝胶}

石墨烯复合气凝胶按照复合体系可分为: 石 墨烯-聚合物复合气凝胶、石墨烯/碳复合气凝胶、 石墨烯/金属氧化物复合气凝胶。

\section{1 石墨烯-有机聚合物复合气凝胶}

石墨烯气凝胶与有机聚合物的复合主要通过 原位生长聚合来实现。石墨烯表面丰富的含氧官 能团可与一系列不同的聚合物单体发生反应, 在 石墨烯表面成功引入聚合物单体, 经原位聚合实 现石墨烯片层与有机聚合物的均匀复合。该策略 可实现高分子聚合物在石墨烯三维网络中的均匀 嵌入, 两组分间的协同效应赋予石墨烯复合气凝 胶优异的力学强度及超级电容性能。 $\mathrm{Li}$ 小组 ${ }^{67}$ 利用 三乙胺改性的氧化石墨烯经水热处理获得氨功能 化石墨烯水凝胶, 随后经三异腈酸酯固化, 超临 界干燥获得三异腈酸酯增强的石墨烯气凝胶。该 气凝胶具有低的块体密度 $\left(0.08 \mathrm{~g} \cdot \mathrm{cm}^{-3}\right)$, 高的压缩 破坏强度 $(0.24 \mathrm{MPa})$ 。Zhang 小组 ${ }^{68}$ 在氧化石墨烯溶 液中均匀引入吡咯单体, 室温静置, 利用 $\mathrm{GO}$ 与吡 咯间的氧化还原反应, 同时实现 GO 的还原与吡咯 的聚合、组装, 经超临界干燥获得石墨烯/聚吡咯 复合气凝胶, 并具有优异的双电层电容与噟电容 性能, 展现出高的比电容值 $\left(304 \mathrm{~F} \cdot \mathrm{g}^{-1}\right)$ 。

将聚合物以网络方式嵌入到石墨烯气凝胶的 三维网络中, 可获得高性能、多功能聚合物纳米 复合材料。 $\mathrm{Li}$ 小组 ${ }^{69}$ 在超轻质弹性石墨烯气凝胶中 添加单体、催化剂、交联剂、引发剂等混合物, 经原位聚合成功制备得到具有良好机械强度、良 好导电性的刺激响应型石墨烯气凝胶基二元网络 水凝胶, 经冷冻干燥获得复合气凝胶材料, 避免 了传统纳米碳颗粒增强聚合物中纳米颗粒难分 散、易聚集等问题。Zhao 小组 ${ }^{70}$ 进一步提出 “渗 透-蒸发-固化” 策略制备得到含聚二甲基硅氧烷的 可压缩石墨烯气凝胶复合材料, 展现出 “粘性” 超疏水性质, 并具有优秀的电化学性质, 可应用 于电化学器件、生物化学分离、微液滴运输、组 织工程学以及微流控芯片领域。

\section{2 石墨烯-碳复合气凝胶}

石墨烯有机聚合物气凝胶经高温碳化可获得 石墨烯基碳复合气凝胶, 同时, 在石墨烯气凝胶 定义不是非常明确的最初发展过程中, 该方法也 常用于制备 “石墨烯气凝胶”。

早期, Ellsworth 小组 ${ }^{71}$ 提及到 GO 和聚乙烯醇
溶液混合物经瞬间冷冻与瞬间热处理可形成石墨 烯基碳气凝胶。随后 Worsley 小组 ${ }^{72}$ 报道了具有高 导电性石墨烯碳气凝胶的制备: 将催化剂碳酸 钠、黏结剂酚醛聚合物 $(\mathrm{RF})$ 分散于 $\mathrm{GO}$ 溶液中, 随 后经酚醛溶胶-凝胶聚合、超临界 $\mathrm{CO}_{2}$ 干燥以及㷽 烧获得具有高比表面积 $\left(584 \mathrm{~m}^{2} \cdot \mathrm{g}^{-1}\right)$ 、介孔结构以 及高导电性 $\left(87 \mathrm{~S} \cdot \mathrm{m}^{-1}\right)$ 的石墨烯/碳复合气凝胶。随 后, 同时充当催化剂与原料的碱性 GO 溶液 ${ }^{73}$ 、改 性的氧化石墨烯 ${ }^{4}$ 、石墨烯水溶液 ${ }^{75}$ 等均实现了高 性能石墨烯/碳复合气凝胶的制备。

石墨烯与碳纳米管作为碳家族中的明星材 料, 在气凝胶材料中的复合受到人们的关注。 Zhang 等 ${ }^{76}$ 将 VC、GO 与碳纳米管混合溶液静置水 浴加热, 经超临界干燥获得石墨烯/碳纳米管复合 气凝胶, 该复合气凝胶展现出非常高的海水淡化 能力 $\left(633.3 \mathrm{mg} \cdot \mathrm{g}^{-1}\right)$ 。 Gao 小组 ${ }^{77}$ 直接冷冻碳纳米管/ 石墨烯水溶液, 制备得到世界上最轻(密度 $\rho \leq$ $0.16 \mathrm{mg} \cdot \mathrm{cm}^{-3}$ ) 的全碳气凝胶, 亦是最轻的固体材 料, 兼具柔性, 在吸附、超级电容器、催化剂载 体以及环境记忆材料等领域都具有非常好的应用 前景。

\section{3 石墨烯-金属氧化物纳米粒子复合气凝胶}

石墨烯独特的二维结构以及高的比表面积使 其成为多种纳米粒子沉积的温床, 无机纳米粒子 的引入能够有效削弱石墨烯片层之间的 $\pi-\pi$ 相互 作用, 同时无机纳米粒子与石墨烯的协同作用赋 予复合材料更为优异的性能, 在锂离子电池、超 级电容器、电催化等领域展现出良好的性能。石 墨烯与无机纳米粒子的复合可分为纳米粒子的嵌 入与原位生长两种方式。

Yan 小组 ${ }^{78}$ 以 “渔网捕鱼” 的例子形象描述了 石墨烯-纳米粒子复合气凝胶的制备原理, 如图 8 所示, 以 “鱼” 代表纳米粒子, 以 “渔网” 代表 还原过程中形成的 $\mathrm{rGO} / \mathrm{GO}$ 网络结构, 揭示大部分 纳米颗粒嵌入到石墨烯气凝胶网络结构中的可能 性, 为新型 $3 \mathrm{D}$ 石墨烯/纳米颗粒复合气凝胶的制备 提供理论基础。并利用化学还原组装实现 $\mathrm{Fe}_{3} \mathrm{O}_{4}$ 纳 米粒子在石墨烯三维网络上的均匀分布, 在锂离 子电池阳极材料应用中展现出优异的倍率性能及 良好的循环稳定性。

同样的组装原理, Qi 小组 ${ }^{79}$ 在石墨烯片层上成 功负载两种不同的纳米粒子, 制备出三元石墨烯 复合气凝胶 $-\mathrm{CdS} / \mathrm{TiO}_{2} /$ 石墨烯复合气凝胶: 将 $\mathrm{CdS}$ 


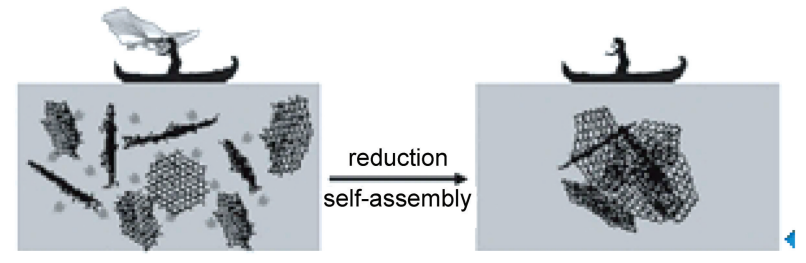

图 83 石墨烯/纳米粒子宏观体的形成(自组装与包裹) 机理示意图 ${ }^{78}$

Fig.8 Proposed self-assembly and wrapping mechanism for 3D graphene/nanoparticles architecture formation ${ }^{78}$

与 $\mathrm{TiO}_{2}$ 纳米粒子加入至 $\mathrm{GO}$ 溶液, 高温水热组装、 冷冻干燥获得复合气凝胶。该样品具有高的比表 面积、连通的导电网络、特殊的微观结构以及优 异的光电化学活性, 如图9所示, 生动描述了多元 复合气凝胶的结构示意图以及光催化反应机理及 各组分间的协同效应, 并在作为光催化剂制氢应 用中表现出高效电荷分离特性及优异的光吸收能 力与耐久性。Chen 小组 ${ }^{80}$ 以一维纳米线和零维纳米 颗粒为例, 系统研究了多元纳米材料复合石墨烯 三维宏观体的构建, 详细解释了不同形貌纳米材 料复合时石墨烯的组装原理, 并以 $\mathrm{TiO}_{2}$ 纳米颗粒 及聚苯胺体系为例, 通过优化质量分布, 实现了 高性能电极材料的制备并成功应用于光电化学催 化及超级电容器器件中。

在氧化石墨烯溶液中引入金属离子, 不仅有 助于 $\mathrm{GO}$ 的还原与组装, 还可实现金属氧化物纳米 粒子的同步沉积、生长, 获得多功能石墨烯复合 气凝胶。Zhang 小组 ${ }^{81}$ 报道了铁氰化钾存在时, 采 用维生素 $\mathrm{C}$ 作为还原剂对 $\mathrm{GO}$ 与 $\mathrm{FeCl}_{3}$ 进行还原制 备得到具有 $3 \mathrm{D}$ 多孔网络结构的石墨烯-普鲁士蓝复 合气凝胶, 该复合气凝胶在 $\mathrm{H}_{2} \mathrm{O}_{2}$ 的电催化还原
中, 表现出非常低的检测极限 $\left(5 \times 10^{-9} \mathrm{~mol} \cdot \mathrm{L}^{-1}\right)$ 以 及宽的线性区间 $\left(0.005-4 \mathrm{mmol} \cdot \mathrm{L}^{-1}\right)$ 。 $\mathrm{Yu}$ 小组 ${ }^{33}$ 以 $\mathrm{FeSO}_{4}$ 为还原剂, 在温和的环境 $\left(90^{\circ} \mathrm{C}\right)$ 下一步实现 $\mathrm{GO}$ 的自组装与金属氧化物纳米颗粒的原位同步沉 积, 获得具有 $3 \mathrm{D}$ 连通网络结构的石墨烯/铁氧化物 水凝胶与气凝胶。之后, $\mathrm{Fe}^{3+} 、 \mathrm{Ti}^{3+} 、 \mathrm{Ce}^{3+} 、 \mathrm{Fe}^{2+}$ 、 $\mathrm{Mn}^{2+}$ 、高锰酸钾等作为前驱体用于制备 $3 \mathrm{D}$ 石墨烯/ 金属氧化物纳米颗粒 $\left(\mathrm{Fe}_{3} \mathrm{O}_{4} 、 \mathrm{TiO}_{2} 、 \mathrm{CeO}_{2} 、 \mathrm{Fe}_{2} \mathrm{O}_{3}\right.$ 、 $\mathrm{Mn}_{3} \mathrm{O}_{4}$ 等)复合气凝胶的原位生长复合 ${ }^{82-85}$ 。此外, 在 $\mathrm{FeCl}_{3} \cdot 6 \mathrm{H}_{2} \mathrm{O}$ 与 $\mathrm{GO} / \mathrm{N}, \mathrm{N}$-二甲基甲酰胺分散液中引 入表氯醇(环氧氯丙烷), 可实现在石墨烯气凝胶中 原位引入双网络复合体系, 同时该双网络体系表 现出高的饱和磁化强度 $\left(23-54 \mathrm{emu} \cdot \mathrm{g}^{-1}\right)$ 、优异的 生物催化活性及循环使用性 ${ }^{86}$ 。多种金属离子于石 墨烯表面进行同步沉积, 体现出不同石墨烯/金属 氧化物纳米粒子制备的共性, 为新型纳米功能材 料制备提供可借鉴的经验。

$\mathrm{Lin}$ 小组 ${ }^{87}$ 将 $\mathrm{ZnO}$ 纳米种子沉积于石墨烯气凝 胶网络中, 随后进行水热生长, 获得负载 $\mathrm{ZnO}$ 纳 米线的石墨烯复合气凝胶。该生长策略避免了石 墨烯片层对纳米线生长造成的干扰, 实现纳米线 在石墨烯气凝胶网络上的均匀分布及垂直生长, 为锂离子扩散提供合适的微观结构, 极大地优化 了锂离子电池阳极材料的性能。

\section{6 元素掺杂石墨烯气凝胶}

石墨烯气凝胶的元素掺杂 $(\mathrm{N} 、 \mathrm{~B} 、 \mathrm{~S}$ 等)可实现 对石墨烯片层的修饰、改性, 调控其表面化学、 元素组成、导电类型及电化学活性位点等, 增强 并扩展石墨烯气凝胶的性能与应用, 尤其是在燃
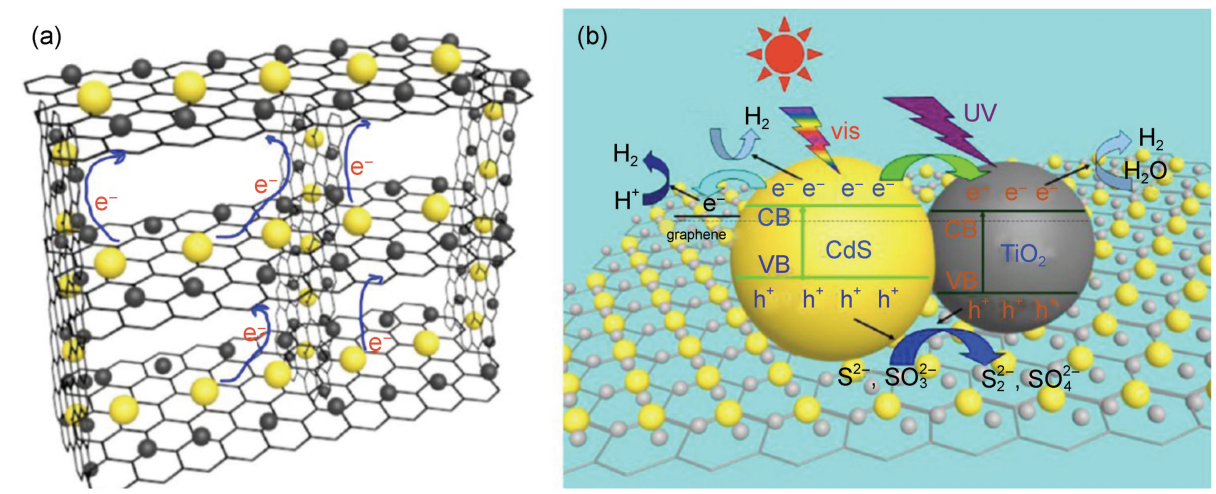

图 $93 \mathrm{D} \mathrm{CdS/TiO} /$ 石墨烯气凝胶网络结构示意图(a)以及该复合气凝胶在阳光照射下的光催化制氢反应机理(b) ${ }^{79}$

Fig.9 Schematic structure of 3D CdS/ $\mathrm{TiO}_{2}$ /graphene aerogel network (a), illustration of the proposed reaction mechanism for hydrogen production over the $\mathrm{CdS} / \mathrm{TiO}_{2} /$ graphene aerogel under irradiation of simulated sunlight (b) $)^{79}$

CB: conduction band; VB: valence band 
料电池氧还原催化剂、锂离子电池与超级电容器 电极材料、吸附与电化学传感等领域有着重要的 应用 ${ }^{8}$ 。目前, 科研人员在 $\mathrm{NH}_{3}$ 氛围下退火处理石 墨烯气凝胶 ${ }^{89} 、 \mathrm{Ar}$ 氛围下退火处理石墨烯-聚吡咯 复合气凝胶 ${ }^{90}$, 均可获得 $\mathrm{N}$ 掺杂石墨烯气凝胶, 并 证明掺杂在碳原子晶格中的氮原子以吡啶氮、吡 咯氮和石墨氮三种成键方式存在。此外, 引入不 同的元素源, 可实现元素的液相掺杂。如在 GO 溶 液中引入环六亚甲基四胺 ${ }^{91}$ 、氨水 ${ }^{92}$ 、尿素 ${ }^{93}$ 、或聚 吡咯 ${ }^{94}$ 等氮源, 经水热处理、冷冻干燥及热退火处 理, 均可获得 $\mathrm{N}$ 掺杂的石墨烯气凝胶; 采用类似 的方法, 以 $\mathrm{Na}_{2} \mathrm{~S}$ 为硫源可实现石墨烯气凝胶的 $\mathrm{S}$ 掺杂 ${ }^{95}$; 以嗍酸为嗍源实现 $\mathrm{B}$ 掺杂 ${ }^{96}$, 采用 $\mathrm{NH}_{3} \mathrm{BF}_{3}$ 可实现 B-N 共掺杂 ${ }^{96}$ 。

\section{7 结论与展望}

目前, 石墨烯气凝胶主要有两种组装策略, 一是基于氧化石墨烯的溶胶-凝胶化学或凝固浴经 湿法组装而得; 二是基于 CVD 法在合适的基底上 经 $3 \mathrm{D}$ 生长而得。CVD石墨烯气凝胶可实现石墨烯 的三维无缝连接, 获得更接近于本征石墨烯的三 维宏观形态, 但成本高, 化学反应相对单一, 受 模板、生长环境影响较大。湿法组装而得的石墨 烯气凝胶具有丰富的种类, 具有诸多可操作性, 受到关注较多。目前对于石墨烯气凝胶的研究主 要集中于湿法组装。

湿法组装的石墨烯气凝胶涉及湿凝胶的组装 及其干燥。在凝胶的组装过程中, 可通过调控前 驱体的浓度、 $\mathrm{pH}$ 值、反应环境(温度、容器形状 等)、体系组分等因素调控气凝胶的宏观性能、密 度、比表面积、孔尺寸分布及机械强度等; 通过 引入不同复合前驱体, 可赋予复合气凝胶各组分 的协同效应及丰富的性能; 通过引入软模板等实 现石墨烯气凝胶宏孔结构的构建, 可获得弹性气 凝胶。干燥过程对于石墨烯气凝胶的制备尤为重 要, 目前石墨烯气凝胶干燥方法主要为超临界干 燥与冷冻干燥, 此外还有少量关于常压干燥的报 道。不同干燥方法所获气凝胶材料的性能与应用 各有偏重: 超临界干燥获得的气凝胶具有较高的 机械强度、高的比表面积等, 是高性能超级电容 器理想的电极材料; 冷冻干燥过程中具有冰晶诱 导效应, 可赋予石墨烯气凝胶可观的弹性、可压 缩性等, 在应力传感等领域展现出诱人的应用前
景; 常压干燥是在冷冻干燥基础上简化而来的, 该技术尚不成熟。

湿法组装和 CVD生长的石墨烯气凝胶均具有 连通的三维多孔网络结构, 表现出较好的机械性 能、高的比表面积、高孔隙率、较高的导电、导 热性等, 在能源存储与转换、吸附、催化及复合 材料等领域有着重要应用, 并受到研究者们的关 注。目前湿法组装均基于氧化石墨烯经片层随机 搭接、堆垛自组装而来, 尚无法操纵石墨烯片层 的有序组装。CVD生长的石墨烯气凝胶受模板基 底的限制, 还不能实现三维石墨烯网络定向生 长。各种方法所获得的石墨烯气凝胶均为各向同 性的无序多孔网络结构, 石墨烯片层的随机搭接 带来严重的石墨烯片层 “边界效应”, 为最优化展 现石墨烯性质及扩展石墨烯宏观体材料的应用带 来极大的障碍。

氧化石墨烯液晶的出现为操纵石墨烯片层有 序排列、组装制备宏观体材料提供最佳前驱体选 择。但目前尚未有关于三维液晶溶胶-凝胶化组装 制备高性能多功能石墨烯气凝胶材料的报道。虽 然 “冰晶模板” 法可获得相对规整的蜂巢状孔结 构, 但多为宏孔结构, 比表面积极低, “边界效 应” 并未有效削弱, 性能与应用仍存在极大限 制。故如何在溶胶-凝胶过程中操纵石墨烯片层的 三维有序排列, 获得高性能的多功能石墨烯气凝 胶, 实现石墨烯性质的最优化展现, 是今后石墨 烯气凝胶组装设计的聚焦之处。而如何实现高性 能石墨烯气凝胶材料的常压干燥, 对于今后工业 化制备高性能石墨烯气凝胶及实现其商业化应用 有着重要意义。因此, 石墨烯气凝胶的组装设计仍 有巨大的优化空间, 相信随着组装设计的不断优 化, 石墨烯气凝胶对各种性能的兼容性将达到一个 新的高度, 进一步拓展石墨烯气凝胶在能源存储与 转换、催化、吸附及传感等领域的智能应用。

\section{References}

(1) Novoselov, K. S.; Geim, A. K.; Morozov, S.; Jiang, D.; Zhang, Y.; Dubonos, S.; Grigorieva, I.; Firsov, A. Science 2004, 306 (5696), 666. doi: 10.1126/science.1102896

(2) Chen, D.; Feng, H.; Li, J. Chem. Rev. 2012, 112 (11), 6027. doi: $10.1021 / \mathrm{cr} 300115 \mathrm{~g}$

(3) Georgakilas, V.; Otyepka, M.; Bourlinos, A. B.; Chandra, V.; Kim, N.; Kemp, K. C.; Hobza, P.; Zboril, R.; Kim, K. S. Chem. Rev. 2012, 112 (11), 6156. doi: 10.1021/cr3000412 
(4) Balandin, A. A.; Ghosh, S.; Bao, W.; Calizo, I.; Teweldebrhan, D.; Miao, F.; Lau, C. N. Nano Lett. 2008, 8 (3), 902. doi: $10.1021 / \mathrm{n} 10731872$

(5) Stoller, M. D.; Park, S.; Zhu, Y.; An, J.; Ruoff, R. S. Nano Lett. 2008, 8 (10), 3498. doi: 10.1021/n1802558y

(6) Bolotin, K. I.; Sikes, K.; Jiang, Z.; Klima, M.; Fudenberg, G.; Hone, J.; Kim, P.; Stormer, H. Solid State Commun. 2008, 146 (9), 351. doi: 10.1016/j.ssc.2008.02.024

(7) Li, C.; Shi, G. Q. Adv. Mater. 2014, 26 (24), 3992. doi: 10.1002/ adma.201306104

(8) Jiang, L.; Fan, Z. Nanoscale 2014, 6 (4), 1922. doi: 10.1039/ c3nr04555b

(9) Zeng, M.; Wang, W. L.; Bai, X. D. Chin. Phys. B 2013, 22 (9), 098105. doi: 10.1088/1674-1056/22/9/098105

(10) Tang, J. J.; Di, F.; Xu, X.; Xiao, Y. H.; Che, J. F. Prog. Chem. 2012, 24 (4), 50. [唐晶晶, 第 凤, 徐潇, 肖迎红, 车剑飞. 化 学进展, 2012, 24 (4), 501.]

(11) Huang, H. Z.; He, Y. Q.; Li, W. Y.; Chu, X. F; Li, Y. M.; Chen, H. M.; Liu, D. Y. Acta Phys. -Chim. Sin. 2014, 35 (2), 457. [黄河 洲, 贺蕴秋, 李文有, 储晓菲, 李一鸣, 陈慧敏, 刘德宇. 物理化 学学报, 2014, 35 (2), 457.] doi: 10.3866/PKU. WHXB201501093

(12) Nardecchia, S.; Carriazo, D.; Ferrer, M. L.; Gutierrez, M. C.; del Monte, F. Chem. Soc. Rev. 2013, 42 (2), 794. doi: 10.1039/ c2cs35353a

(13) Shi, W. W.; Yan, F.; Zhou, G. J.; Ye, Z. K.; Xi, F. N. Chemistry 2013, 76 (11), 988. [石微微, 晏 菲, 周国珺, 叶志凯, 奚风娜. 化学通报, 2013, 76 (11), 988.]

(14) Hummers, W. S., Jr.; Offeman, R. E. J. Am. Chem. Soc. 1958, 80 (6), 1339. doi: 10.1021/ja01539a017

(15) Li, D.; Müller, M. B.; Gilje, S.; Kaner, R. B.; Wallace, G. G. Nat. Nanotechnol. 2008, 3 (2), 101. doi: 10.1038/ nnano.2007.451

(16) Tung, V. C.; Allen, M. J.; Yang, Y.; Kaner, R. B. Nat. Nanotechnol. 2009, 4 (1), 25. doi: 10.1038/NNANO.2008.329

(17) Pei, S.; Zhao, J.; Du, J.; Ren, W.; Cheng, H. M. Carbon 2010, 48 (15), 4466. doi: 10.1016/j.carbon.2010.08.006

(18) Zhang, L.; Wang, Z.; Xu, C.; Li, Y.; Gao, J.; Wang, W.; Liu, Y. J. Mater. Chem. 2011, 21 (28), 10399. doi: 10.1039/c0jm04043f

(19) Xu, Y.; Wu, Q.; Sun, Y.; Bai, H.; Shi, G. ACS Nano 2010, 4 (12), 7358. doi: $10.1021 / \mathrm{nn} 1027104$

(20) Huang, C.; Bai, H.; Li, C.; Shi, G. Chem. Commun. 2011, 47 (17), 4962. doi: 10.1039/c1cc10412h

(21) Bai, H.; Li, C.; Wang, X.; Shi, G. J. Phys. Chem. C 2011, 115 (13), 5545. doi: 10.1021/jp1120299

(22) Huang, H.; Lü, S.; Zhang, X.; Shao, Z. Soft Matter 2012, 8 (17), 4609. doi: $10.1039 / \mathrm{c} 2 \mathrm{sm} 25090 \mathrm{j}$

(23) Huang, H.; Chen, P.; Zhang, X.; Lu, Y.; Zhan, W. Small 2013, 9 (8), 1397. doi: 10.1002/small.201202965

(24) Peng, L.; Zheng, Y.; Li, J.; Jin, Y.; Gao, C. ACS Catal. 2015, 5 (6), 3387. doi: 10.1021/acscatal.5b00233
(25) Xu, Y.; Sheng, K.; Li, C.; Shi, G. ACS Nano 2010, 4 (7), 4324. doi: 10.1021/nn101187z

(26) Zhang, L.; Shi, G. J. Phys. Chem. C 2011, 115 (34), 17206. doi: 10.1021/jp204036a

(27) Wang, J. D.; Peng, T. J.; Sun, H. J.; Hou, Y. D. Acta Phys. -Chim. Sin. 2014, 30 (11), 2077. [汪建德, 彭同江, 孙红娟, 侯云丹. 物理化学学报, 2014, 30 (11), 2077.] doi: 10.3866/PKU.WHXB201409152

(28) Hu, K.; Xie, X.; Szkopek, T.; Cerruti, M. Chem. Mater. 2016, 28 (6), 1756. doi: 10.1021/acs.chemmater.5b04713

(29) Sui, Z.; Zhang, X.; Lei, Y.; Luo, Y. Carbon 2011, 49 (13), 4314. doi: 10.1016/j.carbon.2011.06.006

(30) Chen, W.; Yan, L. Nanoscale 2011, 3 (8), 3132. doi: 10.1039/ c1nr10355e

(31) Sheng, K.; Xu, Y.; Li, C.; Shi, G. New Carbon Mater. 2011, 26 (1), 9. doi: 10.1016/S1872-5805(11)60062-0

(32) Chen, M.; Wang, H.; Li, L.; Zhang, Z.; Wang, C.; Liu, Y.; Wang, W.; Gao, J. ACS Appl. Mater. Interfaces 2014, 6 (16), 14327. doi: 10.1021/am5036169

(33) Cong, H. P.; Ren, X. C.; Wang, P.; Yu, S. H. ACS Nano 2012, 6 (3), 2693. doi: 10.1021/nn300082k

(34) Gao, H.; Sun, Y.; Zhou, J.; Xu, R.; Duan, H. ACS Appl. Mater. Interfaces 2013, 5 (2), 425. doi: 10.1021/am302500v

(35) Luan, V. H.; Tien, H. N.; Hoa, L. T.; Nguyen, T. M. H.; Oh, E. S.; Chung, J.; Kim, E. J.; Choi, W. M.; Kong, B. S.; Hur, S. H. J. Mater. Chem. A 2013, I (2), 208. doi: 10.1039/c2ta00444e

(36) Zhang, L.; Chen, G.; Hedhili, M. N.; Zhang, H.; Wang, P. Nanoscale 2012, 4 (22), 7038. doi: 10.1039/c2nr32157b

(37) Pham, H. D.; Pham, V. H.; Cuong, T. V.; Nguyen-Phan, T. D.; Chung, J. S.; Shin, E. W.; Kim, S. Chem. Commun. 2011, 47 (34), 9672. doi: 10.1039/c1cc13329b

(38) Sheng, K.; Sun, Y.; Li, C.; Yuan, W.; Shi, G. Sci. Rep. 2012, 26 (1), 9. doi: 10.1038/srep00247

(39) Li, Y.; Sheng, K.; Yuan, W.; Shi, G. Chem. Commun. 2013, 49 (3), 291. doi: 10.1039c2cc37396c

(40) Liu, Q.; He, M.; Xu, X.; Zhang, L.; Yu, J. New J. Chem. 2013, 37 (1), 181. doi: 10.1039/c2nj40493a

(41) Hu, C.; Zhai, X.; Liu, L.; Zhao, Y.; Jiang, L.; Qu, L. Sci. Rep. 2013, 3 (6), 2065. doi: 10.1038/srep02065

(42) Maiti, U. N.; Lim, J.; Lee, K. E.; Lee, W. J.; Kim, S. O. Adv Mater. 2014, 26 (4), 615. doi: 10.1002/adma.201303503

(43) Zhang, X.; Sui, Z.; Xu, B.; Yue, S.; Luo, Y.; Zhan, W.; Liu, B. J. Mater. Chem. 2011, 21 (18), 6494. doi: 10.1039/c1jm10239g

(44) Nguyen, S. T.; Nguyen, H. T.; Rinaldi, A.; Nguyen, N. P.; Fan, Z.; Duong, H. M. Colloids Surf. Physicochem. Eng. Aspects 2012, 414 (46), 352. doi: 10.1016/j.colsurfa.2012.08.048

(45) Wu, X.; Zhou, J.; Xing, W.; Wang, G.; Cui, H.; Zhuo, S.; Xue, Q.; Yan, Z.; Qiao, S. Z. J. Mater. Chem. 2012, 22 (43), 23186. doi: $10.1039 / \mathrm{c} 2 \mathrm{jm} 35278 \mathrm{~h}$

(46) Tang, Z.; Shen, S.; Zhuang, J.; Wang, X. Angew. Chem. Int. Edit. 2010, 49 (27), 4603. doi: 10.1002/anie. 201000270 
(47) Jiang, X.; Ma, Y.; Li, J.; Fan, Q.; Huang, W. J. Phys. Chem. C 2010, 114 (51), 22462. doi: 10.1021/jp108081g

(48) Chen, M.; Zhang, C.; Li, X.; Zhang, L.; Ma, Y.; Zhang, L.; Xu, X.; Xia, F.; Wang, W.; Gao, J. J. Mater. Chem. A 2013, 1 (8), 2869. doi: $10.1039 / \mathrm{c} 2 \mathrm{ta} 00820 \mathrm{c}$

(49) Li, Y. R.; Chen, J.; Huang, L.; Li, C.; Hong, J. D.; Shi, G. Q. Adv. Mater. 2014, 26 (28), 4789. doi: 10.1002/adma.201400657

(50) Menzel, R.; Barg, S.; Miranda, M.; Anthony, D. B.; Bawaked, S. M.; Mokhtar, M.; Al-Thabaiti, S. A.; Basahel, S. N.; Saiz, E.; Shaffer, M. S. P. Adv. Funct. Mater. 2015, 25 (1), 28. doi: 10.1002/adfm.201401807

(51) Barg, S.; Perez, F. M.; Ni, N.; do Vale Pereira, P.; Maher, R. C.; Garcia-Tuñon, E.; Eslava, S.; Agnoli, S.; Mattevi, C.; Saiz, E. Nature Communications 2014, 5, 4328. doi: 10.1038/ ncomms 5328

(52) Hu, H.; Zhao, Z. B.; Wan, W. B.; Gogotsi, Y.; Qiu, J. S. Adv. Mater. 2013, 25 (15), 2219. doi: 10.1002/adma.201204530

(53) Qiu, L.; Bulut Coskun, M.; Tang, Y.; Liu, J. Z.; Alan, T.; Ding, J.; Truong, V. T.; Li, D. Adv. Mater. 2016, 28 (1), 194. doi: 10.1002/adma.201503957

(54) Xu, Z.; Zhang, Y.; Li, P. G.; Gao, C. ACS Nano 2012, 6 (8), 7103. doi: $10.1021 / \mathrm{nn} 200069 \mathrm{w}$

(55) Yang, H.; Zhang, T.; Jiang, M.; Duan, Y.; Zhang, J. J. Mater Chem. A 2015, 3 (38), 19268. doi: 10.1039/c5ta06452j

(56) Coraux, J.; N'Diaye, A. T.; Busse, C.; Michely, T. Nano Lett. 2008, 8 (2), 565. doi: 10.1021/n10728874

(57) De Arco, L. G.; Zhang, Y.; Kumar, A.; Zhou, C. IEEE Trans. Nanotechnol. 2009, 8 (2), 135. doi: 10.1109/ TNANO.2009.2013620

(58) Reina, A.; Jia, X.; Ho, J.; Nezich, D.; Son, H.; Bulovic, V.; Dresselhaus, M. S.; Kong, J. Nano Lett. 2008, 9 (1), 30. doi: $10.1021 / \mathrm{n} 1801827 \mathrm{v}$

(59) Li, X.; Magnuson, C. W.; Venugopal, A.; Tromp, R. M.; Hannon, J. B.; Vogel, E. M.; Colombo, L.; Ruoff, R. S. J. Am. Chem. Soc. 2011, 133 (9), 2816. doi: 10.1021/ja109793s

(60) Bae, S.; Kim, H.; Lee, Y.; Xu, X.; Park, J. S.; Zheng, Y.; Balakrishnan, J.; Lei, T.; Kim, H. R.; Song, Y. I. Nat. Nanotechnol. 2010, 5 (8), 574. doi: 10.1038/NNANO.2010.132

(61) Chen, X. L.; Chen, Z. L.; Sun, J. Y.; Zhang, Y. F.; Liu, Z. F. Acta Phys. -Chim. Sin. 2016, 32 (1), 14. [陈旭东, 陈召龙, 孙靖宇, 张 艳锋, 刘忠范. 物理化学学报, 2016, 32 (1), 14.] doi: 10.3866/ PKU.WHXB201511133

(62) Chen, Z.; Ren, W.; Gao, L.; Liu, B.; Pei, S.; Cheng, H. M. Nat. Mater. 2011, 10 (6), 424. doi: 10.1038/NMAT3001

(63) Dong, X.; Wang, X.; Wang, L.; Song, H.; Zhang, H.; Huang, W.; Chen, P. ACS Appl. Mater. Interfaces 2012, 4 (6), 3129. doi: $10.1021 / \mathrm{am} 300459 \mathrm{~m}$

(64) Li, W.; Gao, S.; Wu, L.; Qiu, S.; Guo, Y.; Geng, X.; Chen, M.; Liao, S.; Zhu, C.; Gong, Y.; Long, M.; Xu, J.; Wei, X.; Sun, M.; Liu, L. Sci. Rep. 2013, 3 (7), 120. doi: 10.1038/srep02125

(65) Bi, H.; Chen, I. W.; Lin, T.; Huang, F. Adv. Mater. 2015, 27 (39),
5943. doi: $10.1002 /$ adma.201502682

(66) Bi, H.; Lin, T.; Xu, F.; Tang, Y.; Liu, Z.; Huang, F. Nano Lett. 2015. doi: 10.1021/acs.nanolett.5b03923

(67) Li, J.; Wang, F.; Liu, C. J. Colloid Interface Sci. 2012, 382 (1), 13. doi: $10.1016 /$ j.jcis.2012.05.040

(68) Sun, R.; Chen, H.; Li, Q.; Song, Q.; Zhang, X. Nanoscale 2014, 6 (21), 12912. doi: 10.1039/c4nr03322a

(69) Qiu, L.; Liu, D.; Wang, Y.; Cheng, C.; Zhou, K.; Ding, J.; Truong, V. T.; Li, D. Adv. Mater. 2014, 26 (20), 3333. doi: 10.1002/adma.201305359

(70) Hu, H.; Zhao, Z.; Wan, W.; Gogotsi, Y.; Qiu, J. ACS Appl. Mater. Interfaces 2014, 6 (5), 3242. doi: 10.1021/am4050647

(71) Wang, J.; Ellsworth, M. ECS Transactions 2009, 19 (5), 241. doi: $10.1149 / 1.3119548$

(72) Worsley, M. A.; Pauzauskie, P. J.; Olson, T. Y.; Biener, J.; Satcher, J. H.; Baumann, T. F. J. Am. Chem. Soc. 2010, 132 (40), 14067. doi: 10.1021/ja1072299

(73) Meng, F.; Zhang, X.; Xu, B.; Yue, S.; Guo, H.; Luo, Y. J. Mater. Chem. 2011, 21 (46), 18537. doi: 10.1039/c1jm13960f

(74) Lee, Y. J.; Park, H. W.; Kim, G. P.; Yi, J.; Song, I. K. Curr. Appl. Phys. 2013, 13 (5), 945. doi: 10.1016/j.cap.2013.02.005

(75) Marković, Z. M.; Babić, B. M.; Dramićanin, M. D.; Antunović, I. D. H.; Pavlović, V. B.; Peruško, D. B.; Marković, B. M. T. Synth. Met. 2012, 162 (9), 743. doi: 10.1016/j.synthmet. 2012.03.019

(76) Sui, Z. Y.; Meng, Q. H.; Zhang, X. T.; Ma, R.; Cao, B. J. Mater. Chem. 2012, 22 (18), 8767. doi: 10.1039/c2jm00055e

(77) Sun, H.; Xu, Z.; Gao, C. Adv. Mater. 2013, 25 (18), 2554. doi: 10.1002/adma.201204576

(78) Chen, W. F.; Li, S. R.; Chen, C. H.; Yan, L. F. Adv. Mater. 2011, 23 (47), 5679. doi: 10.1002/adma.201102838

(79) Han, W.; Ren, L.; Gong, L.; Qi, X.; Liu, Y.; Yang, L.; Wei, X. L.; Zhong, J. ACS Sus. Chem. Eng. 2013, 2 (4), 2189. doi: $10.1021 / \mathrm{sc} 400417 \mathrm{u}$

(80) Niu, Z.; Liu, L.; Zhang, L.; Shao, Q.; Zhou, W.; Chen, D.; Xie, S. Adv. Mater. 2014, 26 (22), 3681. doi: 10.1002/ adma.201400143

(81) Chen, L.; Wang, X.; Zhang, X.; Zhang, H. J. Mater. Chem. 2012, 22 (41), 22090. doi: 10.1039/c2jm34541b

(82) Xiao, L.; Wu, D.; Han, S.; Huang, Y.; Li, S.; He, M.; Zhang, F.; Feng, X. ACS Appl. Mater. Interfaces 2013, 5 (9), 3764. doi: $10.1021 / \mathrm{am} 400387 \mathrm{t}$

(83) Yin, H.; Zhao, S.; Wan, J.; Tang, H.; Chang, L.; He, L.; Zhao, H.; Gao, Y.; Tang, Z. Adv. Mater. 2013, 25 (43), 6270. doi: 10.1002/adma.201302223

(84) Wu, S. S.; Chen, W. F.; Yan, L. F. J. Mater. Chem. A 2014, 2 (8), 2765. doi: 10.1039/c3ta14387b

(85) Liu, J. H.; Liu, B. H.; Li, Z. P. Acta Phys. -Chim. Sin. 2014, 30 (9), 1650. [刘建华, 刘宾虹, 李洲鹏. 物理化学学报, 2014, 30 (9), 1650.] doi: 10.3866/PKU.WHXB201406181

(86) Chen, L.; Wei, B.; Zhang, X. T.; Li, C. Small 2013, 9 (13), 2331. 
doi: $10.1002 /$ small.201202923

(87) Shuvo, M. A. I.; Khan, M. A. R.; Karim, H.; Morton, P.; Wilson, T.; Lin, Y. ACS Appl. Mater. Interfaces 2013, 5 (16), 7881. doi: 10.1021/am401978t

(88) Chen, X.; He, D. P.; Mu, S. C. Prog. Chem. 2013, 25 (8), 1292. [陈 旭, 何大平, 木士春. 化学进展, 2013, 25 (8), 1292.]

(89) Xue, Y.; Liu, J.; Chen, H.; Wang, R.; Li, D.; Qu, J.; Dai, L. Angew. Chem. Int. Edit. 2012, 51 (48), 12124. doi: 10.1002/ anie. 201207277

(90) Zhao, Y.; Hu, C.; Hu, Y.; Cheng, H.; Shi, G.; Qu, L. Angew. Chem. Int. Edit. 2012, 51 (45), 11371. doi: 10.1002/ anie. 201206554

(91) Moon, I. K.; Yoon, S.; Chun, K. Y.; Oh, J. Adv. Funct. Mater. 2015, 25 (45), 6976. doi: 10.1002/adfm.201502395

(92) Chen, S.; Duan, J.; Jaroniec, M.; Qiao, S. Z. Angew. Chem. Int.
Edit. 2013, 52 (51), 13567. doi: 10.1002/anie.201306166

(93) Su, P.; Guo, H. L.; Peng, S.; Ning, S. K. Acta Phys. -Chim. Sin. 2012, 28 (11), 2745. [苏 鹏, 郭慧林, 彭 三, 宁生科. 物理化 学学报, 2012, 28 (11), 2745.] doi: 10.3866/PKU. WHXB201208221

(94) Wu, Z. S.; Yang, S. B.; Sun, Y.; Parvez K.; Feng, X. L.; Mullen, K. J. Am. Chem. Soc. 2012, 134 (22), 9082. doi: 10.1021/ ja3030565

(95) Chen, L.; Cui, X.; Wang, Y.; Wang, M.; Qiu, R.; Shu, Z.; Zhang, L.; Hua, Z.; Cui, F.; Weia, C.; Shi, J. Dalton Trans. 2014, 43 (9), 3420. doi: 10.1039/c3dt52253a

(96) Wu, Z. S.; Winter, A.; Chen, L.; Sun, Y.; Turchanin, A.; Feng, X.; Müllen, K. Adv. Mater. 2012, 24 (37), 5130. doi: 10.1002/ adma.201201948 